\title{
HIV-associated neurocognitive disorders: a changing pattern
}

\author{
Samanta Simioni', Matthias Cavassini ${ }^{2}$, Jean-Marie Annoni ${ }^{3}$, Bernard Hirschel ${ }^{4}$ \\ \& Renaud A Du Pasquier ${ }^{\dagger 1,5}$ \\ 'Division of Neurology, Centre Hospitalier Universitaire Vaudois (CHUV), Rue du Bugnon 46, 1011 Lausanne. \\ Switzerland \\ 2Division of Infectious Diseases, Centre Hospitalier Universitaire Vaudois (CHUV), Rue du Bugnon 46 \\ 1011 Lausanne, Switzerland \\ BDivision of Neurology, Geneva University Hospital, Rue Gabrielle-Perret-Gentil 4, 1211 Geneva 14, Switzerland \\ «Division of Infectious Diseases, HIV/AIDS Unit, Geneva University Hospital, Rue Gabrielle-Perret-Gentil 4. \\ 1211 Geneva 14, Switzerland \\ 5Department of Immunology, Centre Hospitalier Universitaire Vaudois, rue du Bugnon 46, 1011 Lausanne. \\ Switzerland \\ Author for correspondence: Tel.:+41 213141228 m Fax: +41 213141256 m renaud.du-pasquier@chuv.ch
}

Combination antiretroviral therapy has dramatically decreased the incidence of HIV-related mortality and serious opportunistic diseases, among which is HIVassociated dementia. However, minor forms of cognitive dysfunction have not disappeared and may even have increased in frequency. Aging of HIV+ patients, insufficient penetration of antiretroviral drugs into the brain with continuous lowgrade viral production and inflammation may play a role. A putative neurotoxicity of combination antiretroviral therapy is controversial. In this article, we will discuss these aspects, as well as clinical and pathophysiological features shared by HIV-associated neurocognitive disorders and other neurodegenerative diseases, especially Alzheimer's disease. This article will briefly summarize the current clinical trials on neuroprotective agents, and the management of patients with neurocognitive disorders will be discussed.

\section{MedscapeCME“ Medscape: Continuing Medical Education Online}

This activity has been planned and implemented in accordance with the Essential Areas and policies of the Accreditation Council for Continuing Medical Education through the joint sponsorship of Medscape, LLC and Future Medicine Ltd. Medscape, LLC is accredited by the ACCME to provide continuing medical education for physicians.

Medscape, LLC designates this Journal-based CME for a maximum of 1 AMA PRA Category 1 Credit $(s)^{\mathrm{TM}}$. Physicians should claim only the credit commensurate with their participation in the activity.

All other clinicians completing this activity will be issued a certificate of participation. To participate in this journal CME activity: (1) review the learning objectives and author disclosures; (2) study the education content; (3) take the post-test and/or complete the evaluation at www. medscape.org/journal/fnl; (4) view/print certificate.

\section{Release date: January 21, 2011; Expiration date: January 21, 2012}

\section{Learning objectives}

Upon completion of this activity, participants should be able to:

- Describe changes in the epidemiology of HIV-associated dementia and HANDs

- Describe the pathophysiology underlying HANDs

- Describe the management of patients with HANDs and clinical trials on neuroprotective agents 
Financial \& competing interests disclosure

Editor: Elisa Manzotti, Editorial Director, Future Science Group. Disclosure: Elisa Manzotti has disclosed no relevant financial relationships.

Authors and Credentials: Samanta Simioni, MD, Division of Neurology, Centre Hospitalier Universitaire Vaudois, Switzwerland. Disclosure: Samanta Simioni, MD has disclosed no relevant financial relationships. Matthias Cavassini, MD, Division of Infectious Diseases, Centre Hospitalier Universitaire Vaudois, Switzwerland. Disclosure: Matthias Cavassini, MD, has disclosed no relevant financial relationships. Jean-Marie Annoni, MD, Division of Neurology, Geneva University Hospital, Switzerland. Disclosure: Jean-Marie Annoni, MD, has disclosed no relevant financial relationships. Bernard Hirschel, MD, Division of Infectious Diseases, HIVIAIDS Unit, Geneva University Hospital, Switzerland. Disclosure: Bernard Hirschel, MD, has disclosed no relevant financial relationships. Renaud A Du Pasquier, MD, Division of Neurology, Department of Immunology, Centre Hospitalier Universitaire Vaudois, Switzwerland. Disclosure: Renaud A Du Pasquier, MD, has disclosed that this work was supported by a grant from the Swiss HIV Cohort Study (No 514) and by the SNF PPOOP3-124893.

No writing assistance was utilized in the production of this manuscript.

Editor: Laurie Barclay, MD, Freelance writer and reviewer, Medscape, LLC. Disclosure: Laurie Barclay, MD, has disclosed no relevant financial relationships.

The survival prognosis of HIV infection has dramatically improved in western countries thanks to the introduction of combination antiretroviral therapy (cART). Moreover, the incidence of the classical neurological complications of HIV (e.g., cryptococcal meningitis, cerebral toxoplasmosis, progressive multifocal leukoencephalopathy or primary CNS lymphoma) has also decreased [1]. Nevertheless, despite these notable improvements in immune outcomes, HIV-associated neurocognitive disorders (HANDs) still remain an important issue.

The aim of this article is to discuss the causes and pathogenic mechanisms of the persistence of HANDs in cART-treated patients in order to provide an update on possible therapies and to propose an algorithm for the management of HIV-infected patients susceptible to developing HANDs.

Modification of the spectrum of cognitive disorders in HIV-infected patients

At the beginning of the AIDS epidemic, the most severe form of HAND, HIV-associated dementia (HAD), typically occurred in immunosuppressed patients with low $\mathrm{CD}^{+}{ }^{+} \mathrm{T}$ cells counts [2]. Onset was insidious and the clinical syndrome mimicked subcortical dementia, characterized by mental slowness, forgetfulness, poor concentration and behavioral abnormalities such as lethargy, decreased spontaneity and decreased emotional responses. However, the spectrum and the severity of HANDs seem to have changed in the cART era. To account for this evolution, the diagnostic criteria first developed by the American Academy of Neurology (AAN) in 1991 [3] were refined in 2007 [4] to recognize three conditions, given here in order of increasing severity: HIV-associated asymptomatic neurocognitive impairment (ANI), corresponding with mild-to-moderate cognitive deficits in two or more cognitive domains without difficulties in activities of daily living; HIV-associated mild neurocognitive disorders, corresponding with mild-to-moderate cognitive deficits in two or more cognitive domains accompanied by mild difficulties in activities of daily living; and HAD, corresponding with moderateto-severe cognitive deficits in two or more cognitive domains and moderate-to-severe difficulties in activities of daily living.

While the incidence of HAD has significantly decreased in the cART era [1], its prevalence, as well as the incidence and prevalence of milder forms of HANDs, seem to have remained relatively stable and may even have increased [5]. Overall, the prevalence of HANDs has been reported to range from 15 to more than 50\% according to some studies [5-8], with higher rates reported in patients showing greater comorbidities. For example, coinfection with hepatitis C virus was associated with greater global neuropsychological impairment and increased difficulties in learning, executive functioning and processing speed [9]. However, cART-treated HIV/hepatitis $\mathrm{C}$ virus-coinfected patients do not seem to have a worse course of HANDs than HIV monoinfected patients on cART [10].

Furthermore, the CD4 ${ }^{+} \mathrm{T}$-cell counts among the individuals diagnosed with HAD appear to be higher than those reported before the introduction of CART [11], and the proportion of HAD among the AIDS-defining illnesses has also been reported to have increased [12].

One explanation for these apparently paradoxical phenomena might be retrieved from epidemiological data. In fact, the number of $\mathrm{HIV}^{+}$patients older than 65 years of age has increased tenfold between 1994 and 2004 in the USA, due in part 
to the prolonged survival of HIV-infected patients with advanced immune deficiency as a result of cART [13]. In addition, between 1991 and 1996, the number of new AIDS cases rose twice as fast in persons aged 50 years or older than it did in younger people (22 vs 9\%, respectively) [13]. However, the risk of developing HAD increases in parallel with the aging HIV population; it has been reported that $25 \%$ of $\mathrm{HIV}^{+}$patients aged 50 years or older do exhibit such a neurological condition versus $14 \%$ under the age of 40 years $(\mathrm{p}<0.04)[14]$.

The presence of HANDs has also been studied in stable patients with undetectable viremia and has shown controversial results. In a crosssectional study, such patients were reported to have normal performance on a scale screening for HAND (International HIV Dementia Scale [HDS]) [15]. Furthermore, in a 5-year longitudinal study, no decline was observed in long-term asymptomatic $\mathrm{HIV}^{+}$patients in measures of psychomotor speed [16]. By contrast, other studies reported HANDs despite HIV virological control. We recently estimated that up to $69 \%$ of HIV-infected patients with undetectable plasma HIV viral load might present at least mild cognitive deficits, the majority of those deficits being ANI [8]. Consistent with our data, a study examining cognitive functioning over 27 months, regarding $\mathrm{HIV}^{+}$patients treated with cART, reported a cognitive decline over time in $8-34 \%$ of patients with undetectable viremia [17]. A second study reported a lack of association between incident neurocognitive impairment and virological and immunological measures, thus implying that neural injury continues in some patients despite success of cART [18]. Finally, a cohort study of patients with AIDS reported that $21 \%$ of aviremic patients progressed to HAD [19]. The prevalence of HANDs was quite different among the above studies. These differences probably reflect methodological issues related to the size of the neuropsychological batteries that were used and to the statistical definition of cognitive impairment. Nevertheless, most of the results demonstrate that mild forms of HANDs remain the most prevalent in the cART era, in line with results obtained in the early 1990s, before the ANI diagnostic category was formalized $[20,21]$.

These observations seem to indicate that cART fails to fully prevent cognitive impairment. Thus raising the question as to why are HANDs persist in cART-treated patients. Is the access of cART in the CNS insufficient, thus allowing a chronic lowgrade viral replication within the CNS? Is cART toxic for the brain? Is there a mechanism occurring independently of cART? These questions are currently under investigation. Before reviewing them, a re-examination of the neuropathology of HIV infection might help in understanding the mechanisms at play in HANDs.

\section{Physiopathology of HIV infection in the \\ cART era}

Evidence for persistent

neuroinflammation in

cART-treated patients

HIV enters the CNS early after primary infection [22]. As its neurotropism is strong, there is concern that it might establish latent viral reservoirs in which the virus could continue low-grade replication despite cART [23], thus leading to a 'sanctuary' effect in the CNS and to a chronic inflammation typical of HIV encephalopathy.

HIV encephalopathy, the neuropathological correlate of more severe forms of HANDs [24], classically results from the invasion of the brain by HIV-infected mononucleated cells from the peripheral blood. HIV infects perivascular macrophages, microglial cells and astrocytes, with the latter being infected only nonproductively $[22,25]$. Its neuropathological aspect is characterized by multinucleated giant cells and multiple microglial nodules, reactive astrocytosis and diffuse myelin pallor. By contrast, HIV does not infect neurons or oligodendrocytes. The infection of microglial cells triggers an inflammatory reaction, with subsequent release of viral proteins, proinflammatory cytokines, chemokines, nitric oxyde, neopterin, arachidonic acid, glutamate and quinolinic acid, among others.

These inflammation mediators may lead to cell loss via excitotoxic mechanisms, as well as injury to the synaptodendritic complex, leading to disturbed synaptic transmission mediated by the glutamatergic, dopaminergic and cholinergic systems $[26,27]$. However, HIV infection can also affect cell functioning by interfering directly with intracellular mechanisms. Autophagy and the immunoproteasome system (ubiquitin proteasome system) are the major intracellular pathways for the degradation and recycling of proteins and cytoplasmic organelles. These systems are disturbed by chronic HIV infection, which may lead to the accumulation of cellular waste and ultimately neuronal degradation $[28,29]$.

In the pre-cART era, HIV encephalopathy could be detected particularly in the basal ganglia and the central white matter. The neocortical grey matter, brainstem and cerebellum were sometimes involved, but to a lesser extent [30]. In cART-treated patients, neuroinflammation 
has not diminished, but its pattern has changed: pronounced inflammation is now found in the hippocampi and adjacent parts of the entorhinal and temporal cortices in the autopsied brains of cART-treated patients [30]. These findings correlate with clinical observations in cART-treated patients that suggest an increasing involvement of the hippocampus in HIVrelated cognitive dysfunction, as characterized by decreased memory learning [7,11].

Other neuropathological findings described in cART-treated patients share several features with neurodegenerative diseases. These will be described below.

\section{Neurodegenerative mechanisms related to HIV infection}

According to some authors, HIV infection might speed up the natural process of aging. Indeed, the cognitive profile of HIV-infected patients appears quite similar to that observed in normal aging. In particular, cognitive abilities such as learning, attention, working memory and processing speed are affected in both conditions, whereas language, remote memory and visuospatial skills remain preserved [31]. From a histopathological point of view, HIV infection and normal aging both lead to white matter atrophy preferentially involving the frontostriatal tracks, diminished production of myelin by the oligodendrocytes located in the frontal lobes, hippocampal neuronal loss and alteration of the BBB [31].

The longer duration of HIV disease combined with the increasing age of HIV-infected patients may also play a role in the development of several neurodegenerative diseases [31]. Indeed, there are neuroimmunopathological similarities between HIV infection and neurodegenerative disorders, such as activation of microglia and astrocytes [32], increases of proinflammatory cytokines (e.g., TNF- $\alpha$ and IL-6) [33] and chemokines (MCP-1) in both serum and cerebrospinal fluid (CSF) [34] or decreased immune surveillance [35].

More specifically, HIV has common features with Parkinson's disease and Alzheimer's disease (AD). In fact, both Parkinson's disease and HIV diseases affect substantia nigra and induce dopaminergic [31] and testosterone deficits [36]. With regard to $\mathrm{AD}$, cART-treated $\mathrm{HIV}^{+}$patients also share several risk factors with patients suffering from this pathology, such as insulin resistance, testosterone deficit or increase of cholesterol [31]. In one series, apoE4, an accepted risk factor for AD, was expressed twice as much in HIVinfected individuals with dementia compared with infected individuals without dementia [37].
Some evidence also suggests that the location of selective neuronal loss described in HAD mimics that of $\mathrm{AD}$, with larger degrees of hippocampal neuronal cell loss in the earlier stages. Amyloid plaques have been identified in the brains of AIDS patients, with a significantly higher frequency in older compared with younger individuals. In addition, amyloid- $\beta$ precursor protein (APP) was detected in the brains of $27 \%$ of asymptomatic $\mathrm{HIV}^{+}$patients, demonstrating that there is an early deposit of this neurotoxic protein in these patients [38]. Tat, the regulatory protein of HIV, inhibits neprilysin, a neuronal endopeptidase known to degrade amyloid- $\beta$. This may be the reason why amyloid- $\beta$ deposition increases in $\mathrm{HIV}^{+}$patients [39]. Finally, prolonged exposure to cART (e.g., to ritonavir, which is known to inhibit amyloid clearance from the brain) and aging may account for the overall increase of amyloid deposition in $\mathrm{HIV}^{+}$patients [40]. Contrasting with these findings, Ances et al. assessed amyloid deposition in older cognitively unimpaired $\mathrm{HIV}^{+}$ patients (mean age: 52 years) by using in vivo amyloid imaging with ${ }^{11} \mathrm{C}-\mathrm{PiB}$ PET technology and reported that HIV patients did not have more fibrillar brain amyloid deposition [41]. However, these authors did find a diminished level of the neuropathological form of amyloid- $\beta, A \beta 1-42$, in the CSF, similar to those patients with AD.

\section{Are there specific biomarkers of HIV-associated neurocognitive disorders?} Based on some similarities between AD and HANDs, the validity of biomarkers described initially in AD has been assessed in HAND patients. In $\mathrm{AD}$, typical CSF changes include a decrease in A $\beta 1-42$ and an increase in tau protein [42]. Similar to AD, a low level of the toxic form of A $\beta 1-42$ was found in the CSF of patients with HANDs [43] together with a normal CSF level of A $\beta 1-40$, indicating brain amyloid deposition and not just death of neurons [44]. However, the results regarding tau are discordant between studies: some found an increase of tau in the CSF of patients with HANDs, similar to those with AD [43], whereas others found no increase of CSF tau, either in its total form or its phosphorylated one [44-46], thus offering a distinct profile of HAND as compared with AD. Recently, Gisslen et al. carried out a comprehensive study of several biomarkers and found that the CSF combination of a low level of soluble APPs (sAPPs) $-\alpha$ and $-\beta$ and a normal level of phosphorylated tau allowed the discrimination of patients with HAD from both $\mathrm{HIV}^{+}$and $\mathrm{HIV}^{-}$neuroasymptomatics and from $\mathrm{AD}$ patients, but not from those 
$\mathrm{HIV}^{+}$patients with opportunistic infections [47]. They concluded that parallel reductions of CSF sAPP- $\alpha$ and sAPP- $\beta$ in HAD and opportunistic CNS infections suggest an effect of CNS immune activation or inflammation in neuronal amyloid synthesis or processing [47].

Taken together, these data point to a multifactorial etiology of HANDs, located at the interface between infection, inflammation and neurodegeneration. Considering this complex situation, is it possible to successfully treat, and even prevent, HANDs?

\section{Current knowledge on cART efficacy for the brain \\ CART penetration-effectiveness in the CNS}

A number of mechanisms affect the CNS concentration of cART by limiting the access to drugs into and within CNS compartments. In particular, anatomical barriers such as the BBB, the blood-CSF barrier and the CSF-brain barrier play a crucial role.

In the current anti-HIV armamentarium, nevirapine, indinavir, lopinavir, amprenavir, abacavir, zidovudine, stavudine, emtricitabine, darunavir and raltegravir are the only drugs found to have CSF levels thar are sufficient to inhibit HIV replication in the brain [48].

In 2008, based on the actual knowledge on cART pharmacokinetic characteristics, CSF concentrations and effectiveness in suppressing CNS viral replication as reported in previously published studies, Letendre et al. designed a score to measure the CNS penetration-effectiveness (CPE) of antiretroviral therapies [49]. The CPE score for a targeted cART regimen is obtained by summing individual drug scores. By computing the CPE rank, it becomes possible to evaluate the CNS efficacy of a given cART regimen. Letendre et al. found that lower CPE scores were associated with higher CSF viral loads [49]. Other recent publications confirmed that antiretroviral drugs with higher CPE score were the most efficient in suppressing HIV replication in the CSF [50,51].

With regard to HANDs, the value of the CPE score is more controversial. In a recent longitudinal study in which the authors followed up cognitively impaired patients initiating a new cART regimen for 48 weeks, Cysique et al. found that cognition gradually improved after initiating cART, with a peak at approximately 24-36 weeks [50]. In addition, they showed that a high CPE score significantly predicted neuropsychological improvement. Along the same lines, another follow-up study of patients changing or initiating cART reported that CPE scores correlated with greater improvement in neuropsychological measures of concentration, speed of mental processing and mental flexibility after 20 and 39 months. Higher CPE scores were also associated with an improvement in global neuropsychological scores after 39 months [52]. By contrast, other studies did not report a beneficial effect of cART with high CPE scores $[8,51]$. This CPE ranking system has been recently revised to integrate new drugs (Table $\mathbf{1}$ ).

In conclusion, the CPE score is certainly an interesting concept, but prospective studies are needed in order to validate it as a clinical tool. An added level of complexity comes from the fact that new drugs are regularly arriving on the market and thus this score will have to be updated often, which may render comparison between studies complicated.

In the meantime, the question remains as to whether the lack of cognitive improvement in some cART-treated patients might be related to CNS toxicity of cART, which might hide or limit the cognitive benefit of the treatment.

\section{Might CART be neurotoxic?}

The literature reports some cases of worsening of CNS pathologies under cART [53], but given the large cohort of treated patients, these reports are quite rare. In addition, these phenomena seem to result from a transient worsening of preexisting pathologies paradoxically attributable to the so-called immune reconstitution inflammatory syndrome (IRIS) more than from any direct toxicity of cART [54,55]. The frequency of IRIS is disputed, ranging from 0.9 to $35 \%$ of patients on cART within the first months of therapy [56-57]. In any case, IRIS plays a role in the expression of several AIDS-related CNS disorders such as tuberculosis, cryptococcal disease, cytomegalovirus retinitis and progressive multifocal leukoencephalopathy [55,56]. Indeed, beginning cART soon after the diagnosis of an opportunistic infection might increase the risk of a reactivation [55]. Recently, the detection of the following features were proposed as guidelines for the diagnosis of CNS IRIS [56]:

- A worsening of neurological status after initiation of cART;

- New neuroradiological findings that are suggestive of inflammation, as illustrated by contrast-enhanced lesions on MRI;

- A decrease in plasma HIV viral load of greater than or equal to $1 \log _{10}$; 


\begin{tabular}{|c|c|c|c|c|}
\hline \multirow[t]{2}{*}{ Agent type } & \multicolumn{4}{|c|}{ CNS penetration-effectiveness score } \\
\hline & 4 (very good) & 3 (good) & 2 (fair) & 1 (poor) \\
\hline NRTI & Zidovudine & $\begin{array}{l}\text { Abacavir } \\
\text { Emtricitabine }\end{array}$ & $\begin{array}{l}\text { Didanosine } \\
\text { Lamivudine } \\
\text { Stavudine }\end{array}$ & $\begin{array}{l}\text { Tenofovir } \\
\text { Zalcitabine }\end{array}$ \\
\hline NNRTI & Nevirapine & $\begin{array}{l}\text { Delavirdine } \\
\text { Efavirenz }\end{array}$ & Etravirine & \\
\hline $\mathrm{Pl}$ & Indinavir/r & $\begin{array}{l}\text { Darunavir/r } \\
\text { Fosamprenavir/r } \\
\text { Indinavir } \\
\text { Lopinavir/r }\end{array}$ & $\begin{array}{l}\text { Atazanavir } \\
\text { Atazanavir/r } \\
\text { Fosamprenavir }\end{array}$ & $\begin{array}{l}\text { Nelfinavir } \\
\text { Ritonavir } \\
\text { Saquinavir } \\
\text { Saquinavir/r } \\
\text { Tipranavir/r }\end{array}$ \\
\hline Entry inhibitors & & Maraviroc & & Enfuvirtide \\
\hline Integrase inhibitors & & Raltegravir & & \\
\hline
\end{tabular}

- Symptoms that are not explained by a newly acquired disease or by the unusual course of a pre-existing disease;

- Histopathology that is demonstrative of T-cell infiltration.

There is currently little evidence that cART in itself may be neurotoxic. Some studies reported that nucleoside reverse transcriptase inhibitors may disturb mitochondrial function [58] and that protease inhibitors may affect proteosomal function [59], leading to neuropathy. In neuroimaging studies using magnetic resonance spectroscopy (MRS), decreased $\mathrm{N}$-acetylaspartate levels were reported in $\mathrm{HIV}^{+}$patients treated with stavudine and didanosine compared with $\mathrm{HIV}^{+}$patients taking other antiretrovirals or no cART, revealing possible neuronal damage [60]. Finally, long-term cART regimens were shown to be associated with abnormal blood oxygen level-dependent functional MRI responses during the performance of attention tasks, pointing to the possible exacerbation by cART of HIVassociated brain injury in the frontal lobes [61]. By contrast, other neuroimaging studies suggest that cART is beneficial. Indeed, some authors have reported improved brain function after longer periods of treatment [62] and a decreased amplitude of the blood oxygen level-dependent functional MRI response in patients treated with high CPE score regimens, thus reflecting a reduction of the metabolic demand owing to decreased viral replication within the CNS [63].

The impact of cART on cognitive functioning was also assessed in some studies, leading to controversial results. A longitudinal study by
Cysique et al. reported a negative effect of cART regimens combining ritonavir and another protease inhibitor on motor function and hypothesized that the interaction of ritonavir with other protease inhibitors might enhance their capacity to enter the CNS and induce neurotoxicity [64]. But the most convincing and surprising data suggesting that cART may indeed be detrimental to cognitive functions were recently published by Robertson et al. [65]. Neurocognitive function was assessed as part of the AIDS Clinical Trials Group (ACTG) 5170 study, a multicenter, prospective observational study of HIV-infected subjects who elected to discontinue cART. Following $167 \mathrm{HIV}^{+}$ patients over 96 weeks, these authors demonstrated a gradual neurocognitive improvement in patients who did not resume cART, whereas there were no significant changes in neurocognitive function in the 46 subjects who restarted cART prior to week 96. In an accompanying editorial, Clifford writes that this study raises the concern that the therapy may have toxicity that was not appreciated before and that this report "provides a critical warning that even as therapies are used earlier and longer, greater attention to the impairment that they may generate will be essential." [66]. However, he also emphasizes the fact that the overall effect of cART is largely beneficial for $\mathrm{HIV}^{+}$patients, as has been demonstrated recently [67], and to not prescribe cART based on these results is simply not an option.

Indeed, several other studies support a beneficial effect of cART on HANDs. The improvement of HANDs was found to be proportional to the duration of cART [50]. Along the same lines, we reported that HIV-infected patients with a longer duration of cART treatment tended to have better 
cognitive performances [8]. In a randomized controlled study, Winston et al. recently focused on the beneficial effects of specific antiretroviral agents [68]. Treatment-naive patients were randomly assigned to three different cART regimens of tenofovir-emtricitabine plus efavirenz, atazanavir-ritonavir or zidovudine-abacavir.

They were assessed with neuropsychological examinations and MRS at baseline and after 48 weeks. Results showed greater improvement in neuronal recovery on MRS for patients receiving tenofovir-emtricitabine plus efavirenz, whereas patients receiving tenofovir-emtricitabine plus zidovudine-abacavir demonstrated a greater improvement in cognitive functioning.

In conclusion, the data presented in the literature generally suggest that cART alleviates HANDs. The question of neurotoxicity of cART warrants further studies, but overall, the picture that emerges is that cART is not always sufficient to completely relieve HANDs.

\section{Diagnosis \& management of HIV-infected patients with HIV-associated neurocognitive disorders}

At present, how should we manage patients with HANDs? Certainly, one important challenge relates to the early detection of HANDs in stable and cART-treated patients, and this is especially true for the physicians taking care of $\mathrm{HIV}^{+}$patients in their daily practice.

Recently, Cysique et al. proposed a brief algorithm to identify patients at risk of HANDs [69]. This algorithm was developed on a sample of patients with advanced HIV (stage C3 according to the Centers for Disease Control and Prevention [CDC] classification) and based on variables that have been documented as risk factors for HANDs: age, educational level, plasma viral load, past history of CNS opportunistic infection, hemoglobin levels, HIV duration, cART CNS penetration characteristics and duration of current cART [69]. The reported sensitivity and specificity of this algorithm were 78 and $70 \%$, respectively, for the identification of patients with HANDs [69].

To determine whether $\mathrm{HIV}^{+}$patients do indeed suffer from HAND, ideally, a full neurocognitive battery should be administered to each patient who obtains a significant score from the aforementioned algorithm or who simply complains of cognitive dysfunction. Unfortunately, this option is not realistic as these examinations are time-consuming and are not available in every center. Thus, a screening method to detect HANDs is essential. Currently, a few cognitive screening procedures exist for the detection of HANDs, but none of them are validated to detect minor cognitive disorders in $\mathrm{HIV}^{+}$patients. In the pre-cART era, the HDS was developed to identify HAD, quickly assessing learning, attention, psychomotor speed and visuospatial skills. This scale demonstrated a sensitivity of $80 \%$ when the score was 10 points or less from a maximum of 16 [70]. However, the accuracy of the HDS to detect minor cognitive deficits in cART-treated patients was found to be inappropriate when using the classical cutoff of less than or equal to 10 points [71,72]. We recently administered the HDS to 100 aviremic $\mathrm{HIV}^{+}$patients and reported that a cutoff of less than or equal to 14 points was associated with a sensitivity of $83 \%$, and a predictive value of $92 \%$ to detect mild forms of HANDs, despite a somewhat decreased specificity (63\%) [8].

We propose that patients who complain of cognitive disorders and who have an HDS score of less than 14 should undergo a comprehensive neuropsychological examination. Normative cutoffs and neuropsychological tests should be selected as recommended in the new nosology for HANDs [4].

In cases where cognitive deficits are ascertained, it is important to rule out confounding factors that may mimic or worsen HANDs, in particular other developmental or neurologic conditions such as opportunistic infections/tumors of the CNS, major depression or recent drug or alcohol dependence. Indeed, the observed cognitive deficits and functional limitations should not be explained on the basis of other conditions unrelated to HIV. Follow-up visits may sometimes be mandatory to disentangle the effects of multiple disorders on cognition. The practitioner should rely on the algorithm by Antinori et al. for a detailed procedure of differential diagnosis [4].

In the presence of HANDs in a cART-treated patient without significant confounding factors, one might face two situations. In the first one, plasma HIV viral load may be detectable. In this case, the physician should change cART to a more appropriate regimen, look for genotype resistances or check the patient's compliance. Only in selected cases (suspicion of intracranial process) should ancillary examinations such as brain MRI or lumbar puncture be considered.

In the second situation, plasma HIV viral load may be undetectable. In this case, additional investigations such as brain MRI and lumbar puncture to measure CSF HIV viral load are warranted. If CSF viral load is detectable ( $>20$ copies $/ \mathrm{ml}$ ), whereas viral load is 


\section{Table 2. Review of studies that have assessed the efficacy of neuroprotective drugs.}

\begin{tabular}{|c|c|c|c|c|}
\hline Agents & Sample & Design & Main findings & Ref. \\
\hline \multicolumn{5}{|l|}{ Antioxidants } \\
\hline OPC-14117 (240 mg/day) & $\begin{array}{l}30 \text { patients with } \\
\text { cognitive impairment }\end{array}$ & $\begin{array}{l}\text { 12-week double-blind, placebo- } \\
\text { controlled, randomized study; } \\
\text { follow-up with } \\
\text { neuropsychological tests }\end{array}$ & $\begin{array}{l}\text { Only a trend towards } \\
\text { improvement in cognitive scores }\end{array}$ & [74] \\
\hline $\begin{array}{l}\text { Selegiline ( } 2.5 \mathrm{mg} \\
\text { 3-times/week per os) }\end{array}$ & $\begin{array}{l}36 \text { patients with } \\
\text { cognitive impairment on } \\
\text { stable antiretroviral } \\
\text { regimen }\end{array}$ & $\begin{array}{l}\text { 10-week randomized, double-blind, } \\
\text { placebo-controlled trial; follow-up with } \\
\text { neuropsychological tests }\end{array}$ & $\begin{array}{l}\text { Cognitive improvement on } \\
\text { verbal memory }(p=0.002) \text {; only } \\
\text { a trend towards improvement of } \\
\text { psychomotor speed }\end{array}$ & [75] \\
\hline $\begin{array}{l}\text { Transdermal selegiline } \\
(1.0 \mathrm{mg} / \mathrm{cm} \times \\
\left.15 \mathrm{~cm}^{2} \text { patch }\right)\end{array}$ & $\begin{array}{l}14 \text { patients with } \\
\text { cognitive impairment on } \\
\text { stable antiretroviral } \\
\text { regimen }\end{array}$ & $\begin{array}{l}10 \text {-week placebo-controlled study; } \\
\text { follow-up with } \\
\text { neuropsychological tests }\end{array}$ & $\begin{array}{l}\text { Improvement in verbal learning } \\
(p=0.03) \text { and motor/ } \\
\text { psychomotor function }(p=0.03)\end{array}$ & {$[76]$} \\
\hline $\begin{array}{l}\text { Transdermal selegiline } \\
(6 \mathrm{mg} / 24 \mathrm{~h} \text { or } \\
3 \mathrm{mg} / 24 \mathrm{~h})\end{array}$ & $\begin{array}{l}128 \text { patients with } \\
\text { cognitive impairment }\end{array}$ & $\begin{array}{l}\text { 24-week placebo-controlled study; } \\
\text { follow-up with neuropsychological } \\
\text { tests and proton MRS }\end{array}$ & $\begin{array}{l}\text { No cognitive or functional } \\
\text { benefit; no MRS change }\end{array}$ & {$[77,79]$} \\
\hline $\begin{array}{l}\text { Transdermal selegiline } \\
(6 \mathrm{mg} / 24 \mathrm{~h} \text { or } \\
3 \mathrm{mg} / 24 \mathrm{~h})\end{array}$ & $\begin{array}{l}86 \text { patients with } \\
\text { cognitive impairment }\end{array}$ & $\begin{array}{l}\text { 24-week open-label treatment phase } \\
\text { offered to patients having completed } \\
\text { the } 24 \text {-week placebo-controlled study } \\
\text { above; follow-up with } \\
\text { neuropsychological tests }\end{array}$ & $\begin{array}{l}\text { Improvement in a cognitive } \\
\text { global score (NPZ-8; } p=0.03) \\
\text { and in psychomotor }(p<0.01) \\
\text { fine motor/nonverbal }(p=0.02) \\
\text { and frontal system }(p<0.01) \\
\text { function domains }\end{array}$ & {$[77,78]$} \\
\hline \multicolumn{5}{|l|}{ Antiapoptotic drugs } \\
\hline $\begin{array}{l}\text { Lithium (maintenance of } \\
12-\mathrm{h} \text { trough } \\
\text { concentrations between } \\
0.4-0.8 \mathrm{mEq} / \mathrm{l} \text { ) }\end{array}$ & $\begin{array}{l}8 \text { patients with } \\
\text { cognitive impairment }\end{array}$ & $\begin{array}{l}\text { Single-arm, open-label 12-week pilot } \\
\text { study; follow-up with } \\
\text { neuropsychological tests }\end{array}$ & $\begin{array}{l}\text { Improvement in a clinical global } \\
\text { deficit score }(p=0.008)\end{array}$ & {$[80]$} \\
\hline $\begin{array}{l}\text { Lithium (300 mg } \\
\text { 2-times/day) }\end{array}$ & $\begin{array}{l}13 \text { patients with } \\
\text { cognitive impairment }\end{array}$ & $\begin{array}{l}\text { 10-week open-label study; follow-up } \\
\text { with neuropsychological tests and MRI } \\
\text { (MRS, diffusion tensor imaging and } \\
\text { functional MRI) }\end{array}$ & $\begin{array}{l}\text { No change in cognitive } \\
\text { performance; changes in MRS } \\
\text { metabolite ratios in the frontal } \\
\text { gray matter, suggestive of } \\
\text { improvement }(p<0.03)\end{array}$ & [81] \\
\hline \multicolumn{5}{|c|}{ Calcium channel blockers } \\
\hline $\begin{array}{l}\text { Nimodipine ( } 60 \mathrm{mg} \\
\text { 5-times/day or } 30 \mathrm{mg} \\
\text { 5-times/day) }\end{array}$ & $\begin{array}{l}41 \text { patients with } \\
\text { mild-to-severe AIDS } \\
\text { dementia complex or } \\
\text { HIV-associated } \\
\text { neuropathy }\end{array}$ & $\begin{array}{l}\text { Phase I and Phase II trial, } 16 \text {-week } \\
\text { placebo-controlled study; follow-up } \\
\text { with neuropsychological tests }\end{array}$ & $\begin{array}{l}\text { No significant cognitive change; } \\
\text { only a trend for an improvement } \\
\text { on the higher dose }\end{array}$ & [82] \\
\hline \multicolumn{5}{|l|}{ CCR5 antagonists } \\
\hline $\begin{array}{l}\text { Intranasal peptide } T \\
\text { (2 mg 3-times/day) }\end{array}$ & $\begin{array}{l}215 \text { patients with } \\
\text { cognitive impairment }\end{array}$ & $\begin{array}{l}\text { 6-month double-blind, placebo- } \\
\text { controlled trial; follow-up with } \\
\text { neuropsychological tests }\end{array}$ & No cognitive benefit & [83] \\
\hline \multicolumn{5}{|l|}{ PAF antagonists } \\
\hline Lexipafant (500 mg/day) & $\begin{array}{l}30 \text { patients with } \\
\text { cognitive impairment }\end{array}$ & $\begin{array}{l}\text { 10-week randomized, placebo- } \\
\text { controlled trial; follow-up with } \\
\text { neuropsychological tests }\end{array}$ & $\begin{array}{l}\text { Only a trend toward cognitive } \\
\text { improvement, especially for } \\
\text { verbal memory }\end{array}$ & {$[84]$} \\
\hline \multicolumn{5}{|l|}{ TNF antagonists } \\
\hline $\begin{array}{l}\text { CPI-1189 (50 or } \\
100 \text { mg/day) }\end{array}$ & $\begin{array}{l}64 \text { patients with } \\
\text { cognitive impairment }\end{array}$ & $\begin{array}{l}\text { 10-week randomized, double blind, } \\
\text { placebo-controlled trial; follow-up with } \\
\text { neuropsychological tests }\end{array}$ & $\begin{array}{l}\text { No cognitive benefit, except for } \\
\text { a slight improvement in motor } \\
\text { function on higher doses } \\
(p=0.01)\end{array}$ & [85] \\
\hline
\end{tabular}




\section{Table 2. Review of studies that have assessed the efficacy of neuroprotective drugs.}

\begin{tabular}{|llll}
\hline $\begin{array}{l}\text { Agents } \\
\text { NMDA antagonists }\end{array}$ & Sample & Design & Main findings \\
\begin{tabular}{|lll} 
Memantine (40 mg/day) \\
140 patients with \\
mild-to-severe AIDS \\
dementia complex on \\
stable cART
\end{tabular} & $\begin{array}{l}\text { 16-week Phase II randomized, } \\
\text { double-blind, placebo-controlled trial; } \\
\text { follow-up with neuropsychological } \\
\text { tests and MRS }\end{array}$ & $\begin{array}{l}\text { No cognitive benefit; increase in } \\
\text { the NMDA:creatine ratio in the } \\
\text { frontal white matter }(p=0.04) \\
\text { and parietal cortex }(p=0.02)\end{array}$ \\
on MRS
\end{tabular}

undetectable in the plasma, physicians should assume that the chosen cART regimen is not optimal. The CPE score might be useful in this case to improve cART CPE [49]. Nevertheless, when both plasma and CSF viral loads are undetectable, a change in cART medication may be useless. In this context, and based on what is known of the physiopathology of HANDs, several neuroprotective and/or anti-inflammatory approaches have been attempted.

\section{Focusing on new therapeutic approaches Current data on anti-inflammatory \& neuroprotective drugs}

Several putative neuroprotective agents with different modes of action were administered to patients with HANDs but did not provide strong evidence of efficacy (TaвLE 2). Only the most significant trials are summarized here. For an exhaustive review on this topic, we refer the reader to the review by Rumbaugh et al. [73].

Antioxidants were tried in an attempt to reduce oxidative stress-induced neuronal injury due to the toxic interactions between HIV-infected macrophages and neurons. One study was conducted using OPC-14117, a lipophilic antioxidant, but this showed only a trend toward cognitive improvement [74]. Two studies conducted using selegiline and transdermal selegiline showed significant efficacy on HANDs [75,76], but in larger trials, neither cognitive benefit [77,78] nor changes in brain metabolism were observed [79]. Antiapoptotic drugs (e.g., lithium), which are supposed to prevent or delay neural injury, were also studied. No clear benefit was observed in neuropsychological measures [80,81]. However, in one study, neuroimaging revealed a decrease in the glutamate:glutamine ratio peak in the frontal grey matter, increased fractional anisotropy and decreased mean diffusivity in several brain areas, as well as changes in brain activation patterns, thus suggesting improvement of the HIV-associated CNS injury [81].

Calcium channel blockers (e.g., nimodipine) [82], CCR5 antagonists (e.g., peptide T) [83], PAF antagonists (e.g., lexipafant) [84] and TNF antagonists (e.g., CPI-1189) [85] did not allow clear cognitive improvement.

Finally, in a Phase II study, memantine, an N-methyl-D-aspartate antagonist, did not induce significant improvement in the neuropsychological tests of patients with moderateto-severe neurocognitive impairment during the 16-week treatment duration. However, MRS demonstrated potential neuroprotective effects, as reflected by an improvement of the neuronal metabolism in the frontal white matter and parietal cortex of treated patients [86]. In a subsequent open-label trial, long-term use of memantine for up to 60 weeks did not provide clear evidence of cognitive benefit [87]. In addition to current treatment approaches, agents such as minocycline or valproic acid are under consideration. A putative favorable effect of cholinesterase inhibitors has been hypothesized [88] based on the similarities between HANDs and AD and based on the fact that choline acetyltransferase, a major enzyme in the synthesis of acetylcholine, is markedly diminished in the putamen and hippocampus of simian immunodeficiency virusinfected monkeys early in the course of simian immunodeficiency virus infection [89].

Do all of these treatment trial failures mean that such anti-inflammatory and/or neuroprotective drugs are pointless? This is probably 
not the case. A major pitfall that is common to all kinds of trials studying a neuroprotective agent (not only in the HIV field) is that often these trials are too short to see a putative beneficial effect. Another problem is that we lack precise biomarkers. Finally, it is likely that several of the physiopathological pathways leading to HANDs are redundant, meaning that the future might demonstrate the need for a cocktail of neuroactive drugs, together with optimal neuro-cART [73].

\section{Conclusion}

HIV-associated neurocognitive disorders still occur in HIV-infected patients despite cART, even though HANDs and their functional impacts on patients' daily living appear to be less severe than in the pre-cART era. With the prolonged survival of cART-treated patients, there is concern that HIV speeds up the natural process of aging and may facilitate the expression of several neurodegenerative disorders. The occurrence of HANDs is probably determined by both persistent inflammation within the CNS and neurodegenerative mechanisms that might be similar to those occurring in other neurodegenerative conditions, such as AD. One unsolved question concerns the role of cART in inducing or maintaining HANDs. To date, the data favoring a beneficial effect of cART on HANDs largely outweigh its putative neurotoxic effects; nevertheless, since in the near future patients will probably be treated earlier in the course of their HIV infection (with CD4 $>350 / \mu \mathrm{l}$ ) [90], there should be heightened awareness of the possible long-term neurotoxic side effects of antiretroviral drugs. Clearly, large clinical trials are now needed to answer this question. Finally, as cART is sometimes insufficient to cure or prevent HANDs, the research on immunomodulatory and neuroprotective therapies should be strongly encouraged.

\section{Future perspective}

In the future, drug research will probably continue to focus on three main questions. The first one will be to determine which cART regimen is optimal in terms of preventing and curing HANDs. A concomitant question will be to examine whether cART has neurotoxic effects, and if this is the case, which are the culprit compounds. These questions will not be easily solved, as they will probably require large randomized controlled trials.

\section{Executive summary}

\section{Modification of the spectrum of cognitive disorders in HIV-infected patients}

- The incidence of HIV-associated dementia has decreased in the combination antiretroviral therapy (cART) era but its prevalence has increased.

- The incidence and prevalence of milder forms of HIV-associated neurocognitive disorders (HANDs) have increased.

\section{Evidence for persistent neuroinflammation in CART-treated patients}

- HIV probably reaches the CNS very early upon infection and may trigger a long-lasting low-grade inflammation that is relatively insensitive to CART.

- In CART-treated patients, neuroinflammation does not diminish, but sites of neuroinflammation change towards involvement of the hippocampus and adjacent parts of the entorhinal and temporal cortices.

Neurodegenerative mechanisms related to HIV infection

- HIV shares histopathological similarities with neurodegenerative diseases, in particular Alzheimer's disease.

- ApoE4 was expressed twice as much in HIV-infected individuals with dementia compared with infected individuals without dementia.

- Amyloid plaques have been identified in the brains of AIDS patients.

- Amyloid- $\beta$ precursor protein was detected in the brains of $27 \%$ of asymptomatic HIV+ patients.

\section{CART penetration effectiveness in the CNS}

- Many antiretroviral agents seem to penetrate the CNS poorly.

- The CNS penetration-effectiveness score might help in measuring the CNS efficacy of a given CART regimen, but further studies are needed to assess its validity.

\section{Might CART be neurotoxic?}

- There are significantly more data supporting a favorable effect of CART on HANDs than a detrimental effect. Nevertheless, recent data are troubling and call for greater attention to their putative impairment on cognitive functions.

Management of HIV-infected patients with HIV-associated neurocognitive disorders

- For now, cART remains the best treatment for HANDs.

- An algorithm for the management of patients with HANDs has been designed.

Current data on neuroprotective drugs

- Several putative neuroprotective agents were tested for the treatment of HANDs but without reaching strong evidence of efficacy. 
The second major point concerns the development of new therapies attempting to reduce or prevent neuronal damage. Until now, the results that were obtained with several anti-inflammatory and/or neuroprotective agents were quite disappointing. Newer compounds, possibly given in combination, in large and long-term studies, are needed. Third, it will certainly become more and more important to identify biomarkers that allow for differentiation between patients developing HANDs and those developing other neurodegenerative diseases. Such biomarkers may also be useful for detecting changes in clinical trials testing new compounds for HANDs.

\section{Bibliography}

Papers of special note have been highlighted as:

- of interest

-" of considerable interest

1. Sacktor N, Lyles RH, Skolasky R et al.: HIV-associated neurologic disease incidence changes: multicenter AIDS cohort study, 1990-1998. Neurology 56(2), 257-260 (2001).

2. Johnson RT: Immunodeficiency virus. In: Viral Infections of the Nervous System (2nd Edition). Johnson RT (Ed.). Lippincott-Raven, PA, USA, 287-313 (1998).

3. Nomenclature and research case definitions for neurologic manifestations of human immunodeficiency virus-type 1 (HIV-1) infection. Report of a Working Group of the American Academy of Neurology AIDS Task Force. Neurology 41(6), 778-785 (1991).

4. Antinori A, Arendt G, Becker JT et al.: Updated research nosology for HIVassociated neurocognitive disorders. Neurology 69 (18), 1789-1799 (2007).

- Provides new diagnostic criteria for HIV-associated neurocognitive disorders, recognizing three conditions asymptomatic neurocognitive impairment, mild neurocognitive disorders and HIV-associated dementia - and gives recommendations for the use of neuropsychological tests.

5. McArthur JC: HIV dementia: an evolving disease. J. Neuroimmunol. 157(1-2), 3-10 (2004).

6. Sacktor N, McDermott MP, Marder K et al. HIV-associated cognitive impairment before and after the advent of combination therapy. J. Neurovirol. 8(2), 136-142 (2002).

7. Cysique LA, Maruff P, Brew BJ: Prevalence and pattern of neuropsychological impairment in human immunodeficiency virus-infected/acquired immunodeficiency syndrome (HIV/AIDS) patients across preand post-highly active antiretroviral therapy eras: a combined study of two cohorts. J. Neurovirol. 10(6), 350-357 (2004).

8. Simioni S, Cavassini M, Annoni JM et al.: Cognitive dysfunction in HIV patients despite long-standing suppression of viremia. AIDS 24(9), 1243-1250 (2010).
9. Hinkin $\mathrm{CH}$, Castellon CA, Levine AJ, Barclay TR, Singer EJ: Neurocognition in individuals coinfected with HIV and hepatitis C. J. Addict. Dis. 27(2), 11-17 (2008).

10. Parsons TD, Tucker KA, Hall CD et al:: Neurocognitive functioning and HAART in HIV and hepatitis $\mathrm{C}$ virus coinfection. AIDS 20(12), 1591-1595 (2006).

11. Brew BJ: Evidence for a change in AIDS dementia complex in the era of highly active antiretroviral therapy and the possibility of new forms of AIDS dementia complex. AIDS 18(Suppl. 1), S75-S78 (2004).

12. Dore GJ, Correll PK, Li Y, Kaldor JM, Cooper DA, Brew BJ: Changes to AIDS dementia complex in the era of highly active antiretroviral therapy. AIDS 13(10), 1249-1253 (1999).

13. Stoff DM, Khalsa JH, Monjan A, Portegies P: Introduction: HIV/AIDS and aging. AIDS 18(Suppl. 1), S1-S2 (2004).

14. Valcour V, Shikuma C, Shiramizu B et al.: Higher frequency of dementia in older HIV-1 individuals: the Hawaii Aging with HIV-1 Cohort. Neurology 63(5), 822-827 (2004).

15. Lopardo GD, Bissio E, Iannella Mdel C, Crespo AD, Garone DB, Cassetti LI: Good neurocognitive performance measured by the International HIV Dementia Scale in early HIV-1 infection. J. Acquir. Immune Defic. Syndr. 52(4), 488-492 (2009).

16. Cole MA, Margolick JB, Cox C et al.: Longitudinally preserved psychomotor performance in long-term asymptomatic HIV-infected individuals. Neurology 69(24), 2213-2220 (2007).

17. Cysique LA, Maruff P, Brew BJ: Variable benefit in neuropsychological function in HIV-infected HAART-treated patients. Neurology 66(9), 1447-1450 (2006).

18. Robertson KR, Smurzynski M, Parsons TD et al.: The prevalence and incidence of neurocognitive impairment in the HAART era. AIDS 21(14), 1915-1921 (2007).

19. Sevigny JJ, Albert SM, McDermott MP et al: An evaluation of neurocognitive status and markers of immune activation as predictors of time to death in advanced HIV infection. Arch. Neurol. 64(1), 97-102 (2007).
20. Grant I, Atkinson JH, Hesselink JR et al.: Evidence for early central nervous system involvement in the acquired immunodeficiency syndrome (AIDS) and other human immunodeficiency virus (HIV) infections. Studies with neuropsychologic testing and magnetic resonance imaging. Ann. Intern. Med. 107(6), 828-836 (1987).

21. Heaton RK, Grant I, Butters $\mathrm{N}$ et al.: The HNRC 500 - neuropsychology of HIV infection at different disease stages. HIV Neurobehavioral Research Center. J. Int. Neuropsychol. Soc. 1(3), 231-251 (1995).

22. McArthur JC, Steiner S, Sacktor N, Nath A: Human immunodeficiency virus-associated neurocognitive disorders: mind the gap. Ann. Neurol. 67(6), 699-714 (2010).

- Addresses the therapeutic gaps between the salutary effects of combination antiretroviral therapy (cART) and normalization of neurological function.

23. Alexaki A, Liu Y, Wigdahl B: Cellular reservoirs of HIV-1 and their role in viral persistence. Curr. HIV Res. 6(5), 388-400 (2008).

24. Cherner M, Masliah E, Ellis RJ et al.: Neurocognitive dysfunction predicts postmortem findings of HIV encephalitis. Neurology 59(10), 1563-1567 (2002).

25. Churchill MJ, Wesselingh SL, Cowley D et al.: Extensive astrocyte infection is prominent in human immunodeficiency virus-associated dementia. Ann. Neurol. 66(2), 253-258 (2009).

26. Koutsilieri E, ter Meulen V, Riederer P: Neurotransmission in HIV associated dementia: a short review. J. Neural. Transm. 108(6), 767-775 (2001).

27. Gonzalez-Scarano F, Martin-Garcia J: The neuropathogenesis of AIDS. Nat. Rev. Immunol. 5(1), 69-81 (2005).

- Summarizes the studies carried out to determine the respective contributions of infection and monocyte/macrophage activation to HIV progression.

28. Rajawat YS, Bossis I: Autophagy in aging and in neurodegenerative disorders. Hormones (Athens) 7(1), 46-61 (2008). 
29. Nguyen TP, Soukup VM, Gelman BB: Persistent hijacking of brain proteasomes in HIV-associated dementia. Am. J. Pathol. 176(2), 893-902 (2010).

30. Anthony IC, Bell JE: The neuropathology of HIV/AIDS. Int. Rev. Psychiatry. 20(1), 15-24 (2008).

31. Brew BJ, Crowe SM, Landay A, Cysique LA, Guillemin G: Neurodegeneration and ageing in the HAART era. J. Neuroimmune Pharmacol. 4(2), 163-174 (2009).

-. Reviews the similarities between HIV infection, aging and neurodegenerative disease.

32. Guillemin GJ, Kerr SJ, Brew BJ: Involvement of quinolinic acid in AIDS dementia complex. Neurotox. Res. 7(1-2), 103-123 (2005).

33. Sokolova A, Hill MD, Rahimi F, Warden LA, Halliday GM, Shepherd CE: Monocyte chemoattractant protein-I plays a dominant role in the chronic inflammation observed in Alzheimer's disease. Brain Pathol. 19(3), 392-398 (2009).

34. Bjorkqvist M, Wild EJ, Thiele J et al: : A novel pathogenic pathway of immune activation detectable before clinical onset in Huntington's disease. J. Exp. Med. 205(8), 1869-1877 (2008).

35. Town $\mathrm{T}$, Laouar $\mathrm{Y}$, Pittenger $\mathrm{C}$ et al.: Blocking TGF- $\beta-S m a d 2 / 3$ innate immune signaling mitigates Alzheimer-like pathology. Nat. Med. 14(6), 681-687 (2008).

36. Okun MS, DeLong MR, Hanfelt J, Gearing M, Levey A: Plasma testosterone levels in Alzheimer and Parkinson diseases. Neurology 62 (3), 411-413 (2004).

37. Valcour VG, Shikuma CM, Watters MR, Sacktor NC: Cognitive impairment in older HIV-1-seropositive individuals: prevalence and potential mechanisms. AIDS 18(Suppl. 1), S79-S86 (2004).

38. An SF, Giometto B, Groves $M$ et al: : Axonal damage revealed by accumulation of $\beta$-APP in HIV-positive individuals without AIDS. J. Neuropathol. Exp. Neurol. 56(11), 1262-1268 (1997).

39. Rempel HC, Pulliam L: HIV-1 Tat inhibits neprilysin and elevates amyloid $\beta$. AIDS 19(2), 127-135 (2005).

40. Green DA, Masliah E, Vinters HV, Beizai P, Moore DJ, Achim CL: Brain deposition of $\beta$-amyloid is a common pathologic feature in HIV positive patients. AIDS 19(4), 407-411 (2005).

41. Ances BM, Christensen JJ, Teshome M et al.: Cognitively unimpaired HIV-positive subjects do not have increased ${ }^{11} \mathrm{C}-\mathrm{PiB}$. A case-control study. Neurology 75(2), 111-115 (2010).
42. Shaw LM, Vanderstichele $\mathrm{H}$, Knapik-Czajka M et al.: Cerebrospinal fluid biomarker signature in Alzheimer's disease neuroimaging initiative subjects. Ann. Neurol. 65(4), 403-413 (2009).

43. Brew BJ, Pemberton L, Blennow K, Wallin A, Hagberg L: CSF amyloid $\beta 42$ and tau levels correlate with AIDS dementia complex. Neurology 65(9), 1490-1492 (2005).

44. Clifford DB, Fagan AM, Holtzman DM et al.: CSF biomarkers of Alzheimer disease in HIV-associated neurologic disease. Neurology 73(23), 1982-1987 (2009).

45. Ellis RJ, Seubert P, Motter R et al.: Cerebrospinal fluid tau protein is not elevated in HIV-associated neurologic disease in humans. HIV Neurobehavioral Research Center Group (HNRC). Neurosci. Lett. 254(1), 1-4 (1998).

46. Green AJE, Giovannoni G, Hall-Craggs MA, Thompson EJ, Miller RF: Cerebrospinal fluid tau concentrations in HIV infected patients with suspected neurological disease. Sex. Transm. Infect. 76(6), 443-446 (2000).

47. Gisslen M, Krut J, Andreasson U et al.: Amyloid and tau cerebrospinal fluid biomarkers in HIV infection. BMC Neurol. 9, 63 (2009).

48. Brew BJ: Benefit or toxicity from neurologically targeted antiretroviral therapy? Clin. Infect. Dis. 50 (6), 930-932 (2010).

49. Letendre S, Marquie-Beck J, Capparelli E et al: Validation of the CNS penetrationeffectiveness rank for quantifying antiretroviral penetration into the central nervous system. Arch. Neurol. 65(1), 65-70 (2008).

- Proposes a practical method to measure cART efficacy in the CNS.

50. Cysique LA, Vaida F, Letendre S et al. Dynamics of cognitive change in impaired HIV-positive patients initiating antiretroviral therapy. Neurology 73(5), 342-348 (2009).

51. Marra CM, Zhao Y, Clifford DB et al:: Impact of combination antiretroviral therapy on cerebrospinal fluid HIV RNA and neurocognitive performance. AIDS 23(11), 1359-1366 (2009).

52. Tozzi V, Balestra P, Salvatori MF et al.: Changes in cognition during antiretroviral therapy: comparison of 2 different ranking systems to measure antiretroviral drug efficacy on HIV-associated neurocognitive disorders. J. Acquir. Immune Defic. Syndr. 52(1), 56-63 (2009).

53. Langford TD, Letendre SL, Marcotte TD et al.: Severe, demyelinating leukoencephalopathy in AIDS patients on antiretroviral therapy. AIDS 16(7), 1019-1029 (2002).
54. Gray F, Bazille C, Adle-Biassette H, Mikol J, Moulignier A, Scaravilli F: Central nervous system immune reconstitution disease in acquired immunodeficiency syndrome patients receiving highly active antiretroviral treatment. J. Neurovirol. 11(Suppl. 3), 16-22 (2005).

55. Riedel DJ, Pardo CA, McArthur J, Nath A: Therapy insight: CNS manifestations of HIV-associated immune reconstitution inflammatory syndrome. Nat. Clin. Pract. Neurol. 2(10), 557-565 (2006).

56. Johnson T, Nath A: Neurological complications of immune reconstitution in HIV-infected populations. Ann. NY Acad. Sci. 1184, 106-120 (2010).

57. McCombe JA, Auer RN, Maingat FG, Houston S, Gill MJ, Power C: Neurologic immune reconstitution inflammatory syndrome in HIV/AIDS: outcome and epidemiology. Neurology 72(9), 835-841 (2009).

58. Kohler JJ, Lewis W: A brief overview of mechanisms of mitochondrial toxicity from NRTIs. Environ. Mol. Mutagen. 48(3-4), 166-172 (2007).

59. Piccinini M, Rinaudo MT, Anselmino A et al.: The HIV protease inhibitors nelfinavir and saquinavir, but not a variety of HIV reverse transcriptase inhibitors, adversely affect human proteasome function. Antivir. Ther 10(2), 215-223 (2005).

60. Schweinsburg BC, Taylor MJ, Alhassoon OM et al:: Brain mitochondrial injury in human immunodeficiency virus-seropositive $\left(\mathrm{HIV}^{+}\right)$ individuals taking nucleoside reverse transcriptase inhibitors. J. Neurovirol. 11(4), 356-364 (2005).

61. Chang L, Yakupov R, Nakama H, Stokes B, Ernst T: Antiretroviral treatment is associated with increased attentional load-dependent brain activation in HIV patients. J. Neuroimmune Pharmacol. 3(2), 95-104 (2008).

62. Chang L, Ernst T, Leonido-Yee M et al.: Highly active antiretroviral therapy reverses brain metabolite abnormalities in mild HIV dementia. Neurology 53(4), 782-789 (1999).

63. Ances BM, Roc AC, Korczykowski M, Wolf RL, Kolson DL: Combination antiretroviral therapy modulates the blood oxygen level-dependent amplitude in human immunodeficiency virus-seropositive patients. J. Neurovirol. 14(5), 418-424 (2008).

64. Cysique LA, Maruff P, Brew BJ: Antiretroviral therapy in HIV infection: are neurologically active drugs important? Arch. Neurol. 61(11), 1699-1704 (2004).

65. Robertson KR, Su Z, Margolis DM et al.: Neurocognitive effects of treatment interruption in stable HIV-positive patients in an observational cohort. Neurology $74(16)$, 1260-1266 (2010). 
- Demonstrates that cART discontinuation improves neurocognition in stable $\mathrm{HIV}^{+}$patients.

66. Clifford DB: Therapeutic conundrum: AIDS therapies may be double-edged swords. Neurology 74(16), 1248-1249 (2010).

67. El-Sadr WM, Lundgren JD, Neaton JD et al.; Strategies for Management of Antiretroviral Therapy (SMART) Study Group: $\mathrm{CD}^{+}$count-guided interruption of antiretroviral treatment. $N$. Engl. J. Med. 355(22), 2283-2296 (2006).

68. Winston A, Duncombe C, Li PCK et al: : Does choice of combination antiretroviral therapy (cART) alter changes in cerebral function testing after 48 weeks in treatmentnaive, HIV-1-infected individuals commencing cART? A randomized, controlled study. Clin. Infect. Dis. 50(6), 920-929 (2010).

- Compares the efficacy of three different cART regimens on cognition and shows that tenofovir-emtricitabine plus zidovudine-abacavir improves cognitive functioning.

69. Cysique LA, Murray JM, Dunbar M, Jeyakumar V, Brew BJ: A screening algorithm for HIV-associated neurocognitive disorders. HIV Med. 11(10), 642-649 (2010).

70. Power C, Selnes OA, Grim JA, McArthur JC: HIV Dementia Scale: a rapid screening test. J. Acquir. Immune Defic. Syndr. Hum. Retrovirol. 8(3), 273-278 (1995).

71. Smith CA, van Gorp WG, Ryan ER, Ferrando SJ, Rabkin J: Screening subtle HIV-related cognitive dysfunction: the clinical utility of the HIV dementia scale. J. Acquir. Immune Defic. Syndr. 33(1), 116-118 (2003).

72. Bottiggi KA, Chang JJ, Schmitt FA et al:: The HIV dementia scale: predictive power in mild dementia and HAART. J. Neurol. 260(1-2), 11-15 (2007).

73. Rumbaugh JA, Steiner J, Sacktor N, Nath A: Developing neuroprotective strategies for treatment of HIV-associated neurocognitive dysfunction. Futur. HIV Ther. 2(3), 271-280 (2008).
-. Reviews and analyzes the current knowledge on the therapeutic trials for the treatment of HIV-related neurocognitive disorders.

74. Safety and tolerability of the antioxidant OPC-14117 in HIV-associated cognitive impairment. The Dana Consortium on the Therapy of HIV Dementia and Related Cognitive Disorders. Neurology 49(1), 142-146 (1997).

75. A randomized, double-blind, placebocontrolled trial of deprenyl and thiotic acid in human immunodeficiency virus-associated cognitive impairment. The Dana Consortium on the Therapy of HIV Dementia and Related Cognitive Disorders. Neurology 50(3), 645-651 (1998).

76. Sacktor N, Schifitto G, McDermott MP, Marder K, McArthur JC, Kieburtz K: Transdermal selegiline in HIV-associated cognitive impairment: pilot, placebocontrolled study. Neurology 54(1), 233-235 (2000).

77. Schifitto G, Zhang J, Evans SR et al: A multicenter trial of selegiline transdermal system for HIV-associated cognitive impairment. Neurology 69(13), 1314-1321 (2007).

78. Evans SR, Yeh TM, Sacktor N et al: Selegiline transdermal system (STS) for HIV-associated cognitive impairment: open-label report of ACTG 5090. HIV Clin. Trials. 8(6), 437-446 (2007).

79. Schifitto G, Yiannoutsos CT, Ernst T et al. Selegiline and oxidative stress in HIVassociated cognitive impairment. Neurology 73(23), 1942-1944 (2009).

80. Letendre SL, Woods SP, Ellis RJ et al.: Lithium improves HIV-associated neurocognitive impairment. AIDS 20(14), 1885-1888 (2006).

81. Schifitto G, Zhong J, Gill D et al:: Lithium therapy for human immunodeficiency virus type 1-associated neurocognitive impairment. J. Neurovirol. 15(2), 176-186 (2009).

82. Navia BA, Dafni U, Simpson D et al:: A Phase I-II trial of nimodipine for HIV-related neurologic complications. Neurology 51(1), 221-228 (1998).
83. Heseltine PN, Goodkin K, Atkinson JH et al.: Randomized double-blind placebocontrolled trial of peptide T for HIVassociated cognitive impairment. Arch. Neurol. 55(1), 41-51 (1998).

84. Schifitto G, Sacktor N, Marder K et al.: Randomized trial of the platelet-activating factor antagonist lexipafant in HIVassociated cognitive impairment. Neurological AIDS Research Consortium. Neurology 53(2), 391-396 (1999).

85. Clifford DB, McArthur JC, Schifitto G et al.: A randomized clinical trial of CPI-1189 for HIV-associated cognitivemotor impairment. Neurology 59(10), 1568-1573 (2002).

86. Schifitto G, Navia BA, Yiannoutsos CT et al:: Memantine and HIV-associated cognitive impairment: a neuropsychological and proton magnetic resonance spectroscopy study. AIDS 21(14), 1877-1889 (2007).

87. Zhao Y, Navia BA, Marra CM et al.: Memantine for AIDS dementia complex: open-label report of ACTG 301. HIV Clin. Trials 11(1), 59-67 (2010).

88. Alisky JM: Could cholinesterase inhibitors and memantine alleviate HIV dementia? J. Acquir. Immune Defic. Syndr. 38(1), 113-114 (2005).

89. Koutsilieri E, Czub S, Scheller C et al.: Brain choline acetyltransferase reduction in SIV infection. An index of early dementia? Neuroreport 11(11), 2391-2393 (2000).

90. When To Start Consortium; Sterne JA, May M, Costagliola D et al.: Timing of initiation of antiretroviral therapy in AIDS-free HIV-1-infected patients: a collaborative analysis of 18 HIV cohort studies. Lancet 373(9672), 1352-1363 (2009).

91. Letendre S, Ellis RJ, Deutsch R et al.; for the CHARTER Group: Correlates of time-toloss-of-viral-response in CSF and plasma in the CHARTER Cohort. Presented at: 17th Conference on Retroviruses and Opportunistic Infections (CROI). San Francisco, CA, USA, 16-19 February 2010. 


\section{MedscapeCME HIV-associated neurocognitive disorders: a changing pattern}

To obtain credit, you should first read the journal article. After reading the article, you should be able to answer the following, related, multiple-choice questions. To complete the questions and earn continuing medical education (CME) credit, please go to www.medscape. org/journal/fnl. Credit cannot be obtained for tests completed on paper, although you may use the worksheet below to keep a record of your answers. You must be a registered user on Medscape.com. If you are not registered on Medscape.com, please click on the New Users: Free Registration link on the left hand side of the website to register. Only one answer is correct for each question. Once you successfully answer all post-test questions you will be able to view and/or print your certificate. For questions regarding the content of this activity, contact the accredited provider,CME@ medscape.net. For technical assistance, contact CME@webmd.net. American Medical Association's Physician's Recognition Award (AMA PRA) credits are accepted in the US as evidence of participation in CME activities. For further information on this award, please refer to http://www.ama-assn.org/ama/pub/ category/2922.html. The AMA has determined that physicians not licensed in the US who participate in this CME activity are eligible for AMA PRA Category 1 Credits ${ }^{\text {TM }}$. Through agreements that the AMA has made with agencies in some countries, AMA PRA credit is acceptable as evidence of participation in CME activities. If you are not licensed in the US and want to obtain an AMA PRA CME credit, please complete the questions online, print the certificate and present it to your national medical association.

Activity evaluation: where 1 is strongly disagree and 5 is strongly agree.

\begin{tabular}{|c|c|c|c|c|c|}
\hline & 1 & 2 & 3 & 4 & 5 \\
\hline \multicolumn{6}{|l|}{ The activity supported the learning objectives. } \\
\hline \multicolumn{6}{|l|}{ The material was organized clearly for learning to occur. } \\
\hline \multicolumn{6}{|l|}{ The content learned from this activity will impact my practice. } \\
\hline The activity was presented objectively and free of commercial bias. & & & & & \\
\hline
\end{tabular}

1. Which of the following statements about the epidemiology of HIV-associated dementia and HIV-associated neurocognitive disorders (HANDs) is most likely correct?

A In the combined antiretroviral therapy (CART) era, the incidence of HIV-associated dementia has increased

B In the CART era, the prevalence of HIV-associated dementia has decreased

C In the CART era, the prevalence of milder HANDs has decreased

D In the CART era, the incidence of milder HANDs has increased

2. A 62-year-old man has been treated with CART and now has evidence of mild cognitive impairment. Which of the following statements about the underlying pathophysiology of his cognitive dysfunction is most likely correct?

$\square$ A CART has been proven to have no neurotoxic effects

B HIV may speed up the natural process of aging and facilitate the expression of neurodegenerative disorders

C The putative neurotoxic effects of cART clearly outweigh its beneficial effect on HANDs

D Neuroinflammation in CART-treated patients is decreased and shifted toward the occipital cortex 


\section{CME}

3. Which of the following statements most likely applies to the management of the patient described in question 2?

$\square$ A cART should be discontinued because of neurotoxicity

$\square$ B It is well known which CART regimen is optimal for preventing and curing HANDs

$\square$ C Most existing antiretroviral agents have good central nervous system (CNS) penetration

$\square$ D Results with existing anti-inflammatory and/or neuroprotective agents used to treat HANDs have been disappointing 